\title{
Assessment of vehicle emissions projections in Madrid (Spain) from 2004 to 2012 considering several control strategies
}

\author{
J. Lumbreras ，M. Valdés , R. Borge , M.E. Rodríguez \\ Department of Chemical and Environmental Engineering, Technical University of Madrid (UPM). Jose Gutierrez Abascal, \\ 2, Madrid 28006, Spain \\ Department of Energy and Fluid Mechanics Engineering, Technical University of Madrid (UPM), Jose Gutierrez Abascal, \\ 2, Madrid 28006, Spain
}

\begin{abstract}
Road transport is a major source of air pollutant emissions in European cities. Moreover, vehicle exhaust emissions have been the cause of much concern about the effects of urban air pollution on human health. Local authorities need to develop strategies to control vehicular emissions through technological and socioeconomical measures. For this reason, an efficiency assessment of possible future measures to reduce air pollution is required for future traffic planning, regulatory and fiscal initiatives. This paper presents the assessment of several mobility and technology scenarios that can be used for emission reductions in Madrid (Spain) in the period 2004 2012. Pollutants considered are those related to typical air quality problems in urban areas in Europe $\left(\mathrm{SO}_{2}, \mathrm{NO}_{x}, \mathrm{NMVOC}\right.$, heavy metals, $\mathrm{CO}$ and particulate matter) and $\mathrm{CO}_{2}$ as a greenhouse gas.

Results show an expected increase in mobility but a decreasing trend in future traffic-related emissions, except for $\mathrm{CO}_{2}$. This reduction is due to technological improvements linked to European Legislation for road vehicles (Euro Standards). $\mathrm{CO}_{2}$ emissions are expected to increase because the technological improvements will not be able to counteract the effect of the large mobility increase. With regard to control strategies, the most effective measure for emission reductions is fleet renewal. According to the hypotheses made in the paper, this would reduce, on average, the pollutant emission by $16.04 \%$. With regard to $\mathrm{CO}_{2}$ emissions, the use of biofuels and the decrease in mobility are the most effective measures.
\end{abstract}

Keywords: Mobility plans; Air pollution; Vehicle emissions projections; Urban air quality; Emission control

\section{Introduction}

In 2004, the annual average concentrations of ambient $\mathrm{PM}_{10}, \mathrm{NO}_{2}, \mathrm{CO}$, Benzene and ozone in Madrid were $0.033,0.060,33,0.002$ and $0.033 \mathrm{mg} / \mathrm{m}^{3}$, respectively. Moreover, in 2005 the average number of $\mathrm{PM}_{10}$ 
exceedances (daily average over $50 \mu \mathrm{g} / \mathrm{m}^{3}$ ) were 65 when the EU limit for 2005 is 35 days per year (Madrid City Council, 2005). In addition, vehicular emissions accounted for $75.5 \%, 91 \%$ and $34 \%$ of the total $\mathrm{NO}_{x}, \mathrm{CO}$ and NMVOC emissions, respectively, in the Madrid urban area in 2005 (Madrid City Council, 2006).

In the last few years, some important efforts have been made worldwide to study the effect of strategies to reduce pollutant emissions from road transport. Seika et al. (1998) estimated changes in the concentration of $\mathrm{NO}_{x}$ and other pollutants from vehicle emissions under different traffic control strategies; Sælensminde (2004) presented cost-benefit analyses of walking and cycling planning to reduce the effect of motorized transport; Shrestha et al. (2005) determined cost effective passenger transport technology and energy options to reduce nitrogen oxides emission from the transport sector in Beijing, China during 2005-2020 and also for Beijing; Hao et al. (2006) have evaluated the impact of land use and traffic planning regulation, emission control of in-use vehicles and new vehicles, fuel quality improvement, introduction of clean fuel vehicle technology and fiscal incentives in emission reductions during the last decade.

In Spain, national emission inventories have been recorded for the period 1990-2003 (MMA, 2005). Currently, the inventory is being improved with emission projections. As part of the air quality management, projections are a very useful tool for policy makers (Lumbreras et al., 2008).

This paper deals with the emission projections from transport sector for Madrid, which has the largest urban centre among Spanish cities. Although some specific studies for the transport sector have been done in Spain, none of them has focused on an urban context taking into account several pollutants at the same time (Aríztegui et al., 2004; Burón et al., 2005). In this study, the pollutants considered are the most relevant ones for urban air quality (Colvile et al., 2001), i.e. $\mathrm{SO}_{2}, \mathrm{NO}_{x}, \mathrm{NMVOC}, \mathrm{Pb}, \mathrm{CO}$ and particulate matter (as TSP - Total Solid Particulates, $\mathrm{PM}_{10}$ - particles with aerodynamic diameters (AD) lower than $10 \mu \mathrm{m}$ and $\mathrm{PM}_{2.5}$ - particles with $\left.\mathrm{AD}<2.5 \mu \mathrm{m}\right)$ as well as greenhouse gases emitted by traffic $\left(\mathrm{CH}_{4}, \mathrm{CO}_{2}\right.$ and $\mathrm{N}_{2} \mathrm{O}$ ).

The time period considered in the projections is between 2004 and 2012. However, some values from previous years (1990-2003) were also calculated in order to evaluate the methodology. Official data available from 1990 up to 2003 (Madrid City Council, 2006; Novotec, 2004) have been used to compare the official data curve to the figures calculated in this study. Regression analysis has also been done based on this data. This analysis has been used to evaluate the results and to design the most likely future scenario.

The aim of this study is to give the local government a tool to assess the future air quality in Madrid under several scenarios and how it is possible to improve the most likely scenario applying technical and non-technical measures. Specific policy objectives are focused on the factors that can influence a reduction of emissions, including: (i) the effect of using biofuels, (ii) the effect of reducing private car mobility, (iii) the effect of a fleet renewal in order to improve the technologies used in cars. Another specific objective of the paper is to compare the effect of the measures to reduce pollution between different areas within the city centre.

In order to reach the objectives, the study firstly predicts the emission trend and fuel consumption for the future period under consideration. This is the so called "Base" scenario: it is the most probable provided no additional measures are considered apart from what is already adopted or approved. After that, an evaluation of the effectiveness of a set of measures intended to decrease the emissions is done. Each measure defines a target scenario so that its efficiency in reducing emissions is clearly shown as a comparison with the base scenario figures. The aim of the scenario development is not to accurately predict future emissions but rather to assess the efficiency of different measures in the reduction of pollutant emissions.

\section{Methodology to estimate the emissions}

The method for evaluating the future pollutant emissions from the transport sector is complex as it is not possible just to add the different projected activity rates multiplied by the appropriate emission factor. They have been evaluated for several scenarios using the European Environment Agency (EEA) software COPERT III, version 2.3 (EEA, 2000). The program is able to estimate the fuel consumption and exhaust emissions from vehicles within a specific area during a year. It is necessary to prepare a set of 1510 input data for each year. 


\subsection{Areas considered}

The Greater Madrid Area $\left(8022 \mathrm{~km}^{2}\right.$ ) has been divided into four geographical areas which may be considered as having different traffic patterns (Fig. 1). The largest one corresponds to the whole surface of the Greater Madrid (Area 1 - Greater Madrid Area).

The second zone is a ring area around the City of Madrid excluding the city centre $\left(586.5 \mathrm{~km}^{2}-\right.$ Area $2-$ Second ring). The third zone (Area 3 - First ring) is a city ring within the city of Madrid and it has $15.72 \mathrm{~km}^{2}$. Finally, the last zone considered is the surface of the old city centre ( $4.78 \mathrm{~km}^{2}$ - Area 4 - old city centre). Apart from these zones, the emissions from cars driven throughout a motorway ring road called "M30" have also been analyzed because of its completely different driving pattern.

For each zone, the total mobility has been split according to the percentage of vehicles driven in it. These figures have been obtained as a result of measurements in several traffic-counting stations (Madrid City Council, 2005).

\subsection{Estimation of emissions before the base year}

The following parameters have been evaluated to estimate the past emissions:

(i) the number of vehicles that were driven during the different years,

(ii) the temporal distribution of the maximum and minimum temperatures along the years,

(iii) the mileage,

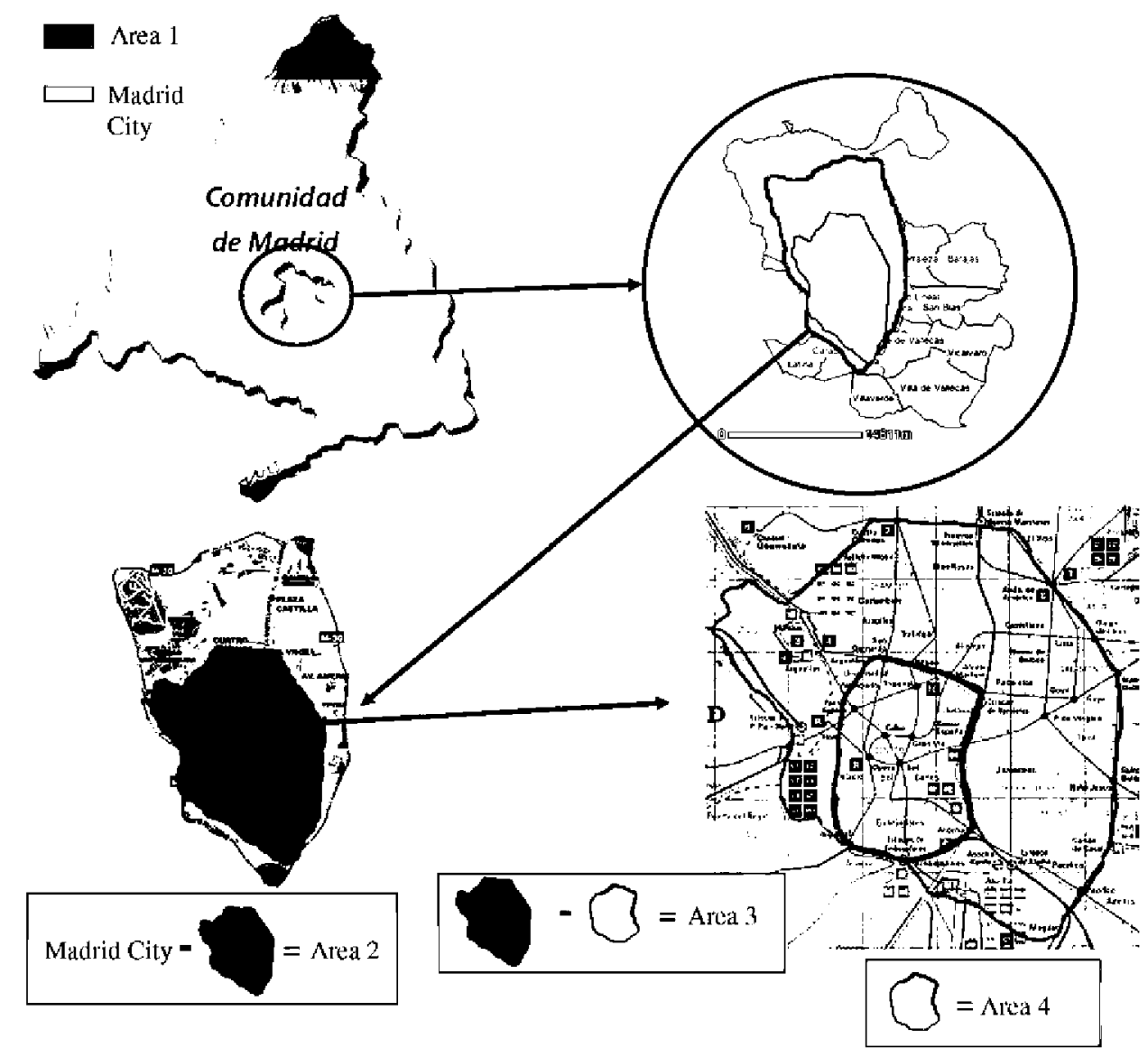

Fig. 1. Split of the total Greater Madrid Surface into different areas with different traffic patterns. 
Table 1

Average speed $(\mathrm{km} / \mathrm{h})$ for each area and type of vehicle considered including the driving pattern for each area according to COPERT guidelines

\begin{tabular}{|c|c|c|c|c|c|c|c|}
\hline \multirow[t]{2}{*}{ Type of vehicle/area } & \multicolumn{3}{|c|}{ Greater Madrid Area (A1) } & \multirow{2}{*}{$\begin{array}{l}\text { Second ring } \\
\text { (A2) } \\
\text { Urban }\end{array}$} & \multirow{2}{*}{$\begin{array}{l}\text { First ring } \\
\text { (A3) } \\
\text { Urban }\end{array}$} & \multirow{2}{*}{$\begin{array}{l}\text { Old city centre } \\
\text { (A4) } \\
\text { Urban }\end{array}$} & \multirow{2}{*}{$\begin{array}{l}\text { Motorway ring } \\
\text { (M30) }\end{array}$} \\
\hline & Rural & Urban & Highway & & & & \\
\hline Cars & 20 & 77 & 102 & 12.52 & 18.89 & 21.11 & 64.1 \\
\hline Light duty vehicles & 20 & 72 & 92 & 12.52 & 18.89 & 21.11 & 64.1 \\
\hline Heavy duty vehicles & 14 & 50 & 70 & 12.52 & 14 & 14 & 64.1 \\
\hline Buses and coaches & 14.6 & 65 & 95 & 14.6 & 14.6 & 14.6 & 64.1 \\
\hline Mopeds & 20 & 40 & - & 20 & 20 & 20 & 64.1 \\
\hline Motorcycles $<250 \mathrm{~cm}^{3}$ & 30 & 70 & 90 & 20 & 20 & 20 & 64.1 \\
\hline Motorcycles $>250$ and $<500 \mathrm{~cm}^{3}$ & 30 & 80 & 102 & 20 & 20 & 20 & 64.1 \\
\hline Motorcycles $>500 \mathrm{~cm}^{3}$ & 30 & 80 & 112 & 30 & 30 & 30 & 64.1 \\
\hline
\end{tabular}

(iv) the average speed, and

(v) the fuel consumption for each type of vehicle.

The number of vehicles, the mileage and the fuel consumption are taken from the yearly statistics published by the regional government (Comunidad de Madrid, 2005).

The average speed has been evaluated for each area using the continuous data calculation system from the Madrid Municipality. A vehicle was used to take values from the zones considered at three different temporal periods (morning, afternoon and evening) having 20 values per day during the entire year. As a result, 7300 values are available for each year with hourly, daily, weekly, monthly and yearly averages. The derived yearly average speeds considered in this study are shown in Table 1.

\subsection{Estimation of the emission projections}

To estimate the future emissions, the number of vehicles that will be driven and their technology have been projected. The increasing number of diesel vehicles used in Spain has been taken into account. Diesel fuel consumption for transport has increased in Madrid by 66\% from 1998 to 2003, while petrol consumption has decreased by $11 \%$. This means that the diesel/petrol ratio consumption in Madrid has changed from 1.04 in 1998 to 1.93 in 2003.

With regard to technology considered, the method takes into account the influence of both current and future main technologies (Euro III, Euro IV and Euro V) changing the fuel consumption and emission factors within COPERT III accordingly (EU, 1998, 2002, 2005b). The possible evolution of new technologies, particularly the fuel cell and electric vehicles, has also been analyzed.

Future mobility for passengers and freights has also been projected using official projections for Gross Domestic Product (GDP), population and fuel consumption (Comunidad de Madrid, 2005; INE, 2005). Passenger mobility is divided into private and public transport. The considered units are passenger $\mathrm{km}$ for passenger mobility and $\mathrm{t} \mathrm{km}$ for freight mobility. However, in both cases, these units are converted into vehicle $\mathrm{km}$ for the emission evaluation. Passengers and freight mobilities in the Greater Madrid Area are shown in Figs. 2 and 3 respectively.

Approved legislation, current data and national projections for other economic parameters have been considered (Fig. 4) to complete all the information required for running COPERT. As a default value, it is assumed that the fuel taxation will not change during the projection period.

\section{Scenarios considered}

The scenarios are based on the methodology used for the emission projections evaluation for Spain (Lumbreras et al., 2008). They reflect hypothetical situations that are interesting from an air quality management and decision making point of view. The scenarios are as follows. 


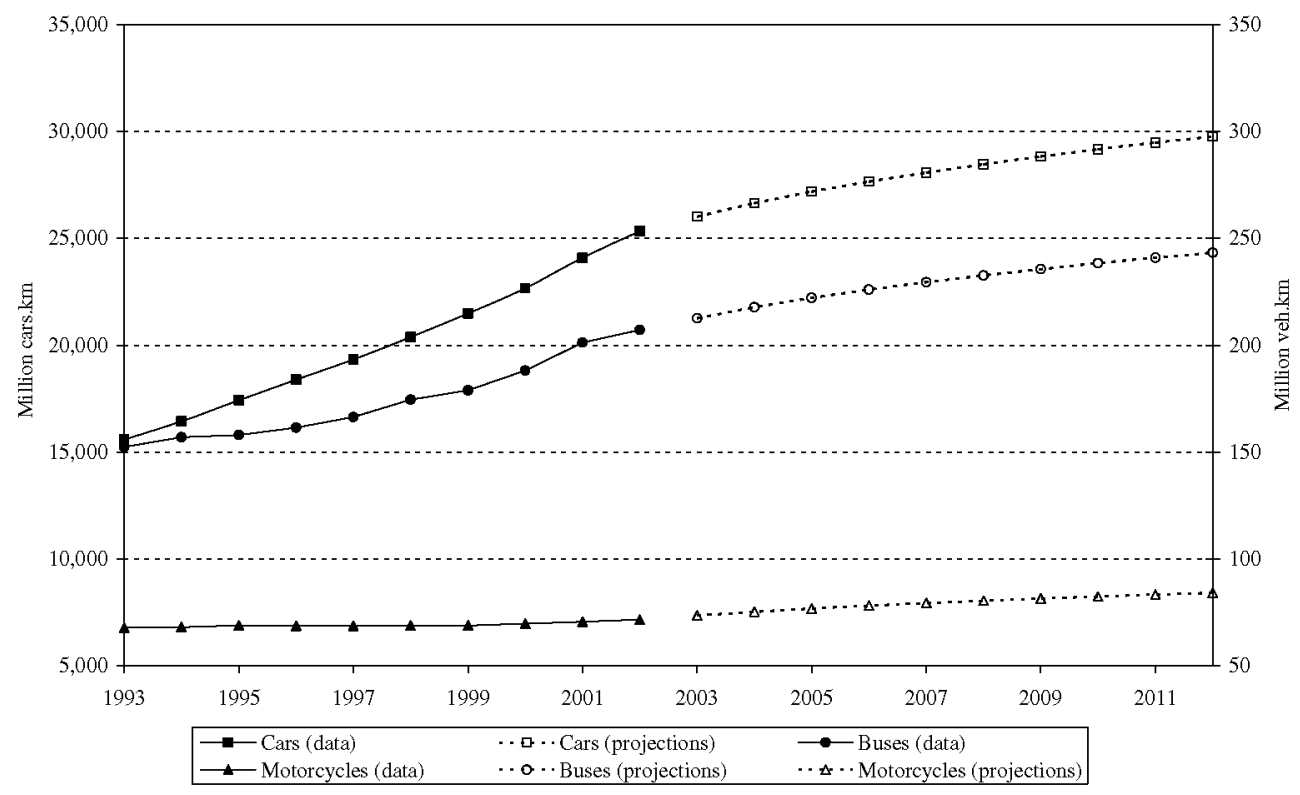

Fig. 2. Mobility for cars, buses and motorcycles in the Greater Madrid Area (A1). Cars mobility is referenced to the left vertical axis while buses and motorcycles correspond to values on the right vertical axis.

\subsection{Base}

The base scenario is intended to provide the emission projections according to the base scenario under the CAFE Program from the European Union (EU, 2005a). It provides estimates under many of the implemented policies and measures for reducing emissions. It has also been defined taking into consideration all plans and measures enacted and in force published by official organizations and all national legislation. Hence, it is supposed to be the most likely scenario.

Apart from this one, three more scenarios have been developed incorporating some additional measures. They are based on the technical references available for the transport sector and also on measures planned by the Ministry of Environment or local authorities (shift from car to public transport, vehicle scrappage programs, change on the driving pattern, use of biofuels, introduction of new vehicle technologies, etc.). Their emissions are evaluated separately to compare their specific improvements.

\subsection{Use of biofuels}

This scenario includes the use of a percentage of fuels produced from biomass, since the emissions associated with their combustion does not account as greenhouse effect gases for Kyoto commitments. The biofuels most commonly used in Spain are biodiesel and biopetrol. Biodiesel is a methyl-ester produced from vegetable or animal oil that complies all diesel standards. It can be used alone or blended with conventional diesel. Pure biodiesel is biodegradable, non-toxic, and almost free of sulphur and aromatic compounds. Its main problems are both a small increase of $\mathrm{NO}_{x}$ emissions and its cost. In Spain, the first biodiesel was sold in March 2003.

Biopetrol is either a blend of conventional petrol and bioethanol or a mix of petrol and Ethyl Tertiary Butyl Ether (ETBE) produced on the basis of bioethanol substituing the Methyl Tertiary Butyl Ether (MTBE) of oilbased petrol.

This scenario has been included due to the recently approved European Directive 2003/30 on the promotion of the use of biofuels or other renewable fuels for transport. It enforces each Member State to ensure that a minimum proportion of biofuels and other renewable fuels are placed on its market, and, to that effect, Member States shall set national indicative targets. As a first step, this value is $2 \%$ of all fuel for transport by 31 December 2005, calculated on the basis of energy content. As a second reference value, each Member 


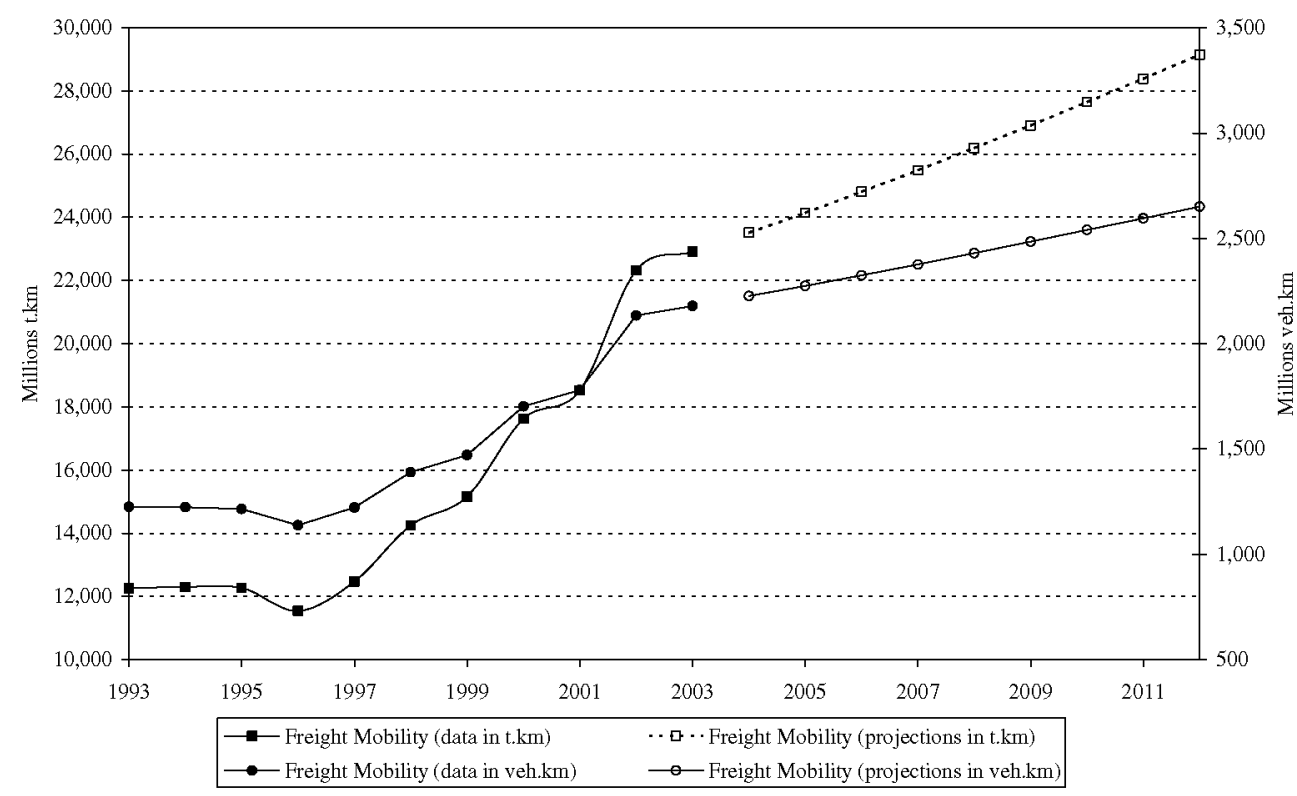

Fig. 3. Mobility for freight transport in the Greater Madrid Area (A1). Mobility in $\mathrm{t} \mathrm{km}$ is read in the left vertical axis, while figures in veh $\mathrm{km}$ units are read in the right vertical axis.

State should have a $5.75 \%$ of all fuel for transport placed on its market by 31 December 2010 , calculated again on the basis of energy content. Two values have been adopted as a target for $2012: 10 \%$ of all diesel for transport purposes and $5.75 \%$ as bioethanol of all petrol transport. Since the average diesel and petrol consumption in terms of energy for Madrid in 2003 were $65.14 \%$ and $34.86 \%$ respectively, and an increase in diesel consumption is expected, these figures should ensure the fulfillment of the Directive before 2011.

\subsection{Decrease in traveled $\mathrm{km}$}

This scenario includes a decrease in traveled $\mathrm{km}$ linked to a change in mobility. An annual car mileage reduction of $1 \%$ compared to the base scenario from 2003 to 2012 is assumed. That will result in an accumulated $10 \%$ reduction for 2012. This decrease would be feasible shifting from private vehicles to public transport (by enlarging underground network, improving bus services and building integrated public transport stations), converting some trafficked city centre areas into pedestrian areas, improving the efficiency (with higher penetration of implemented measures such as car-sharing, park and ride schemes and work mobility plans) and raising public awareness.

\subsection{Fleet renewal}

One of the most efficient measures for reducing air pollution is linked to the overhaul of the fleet through scrappage plans (Dill, 2004; Van Wee et al., 2000; Alberini et al., 1996; Beaton et al., 1995). It allows a vehicle fleet with modern technologies that have better efficiency and lower emissions. In the European Union many initiatives to remove old cars have been done in the 1990s (Greece 1991-1993, Hungary since 1993, France 1994-1996, Denmark 1994, Ireland 1994-1997, Norway 1996 and Italy 1996-1998). In Spain two plans were implemented: the first one in the period 1994-1996 and the second plan is being implemented since 1997. Their influence in fleet renovation is shown in Lisandro and Sampayo (1997).

The specific fleet renewal considered for this scenario is as follows:

- Complete substitution of a technology-type vehicle with a new one when its total percentage from the fleet is lower than the following values: $0.05 \%$ for cars, $0.02 \%$ for heavy duty vehicles with load minor than $32 \mathrm{t}$, $0.005 \%$ for heavy duty vehicles with higher load than $32 \mathrm{t}, 0.01 \%$ for buses and coaches and $0.02 \%$ for motorcycles. 


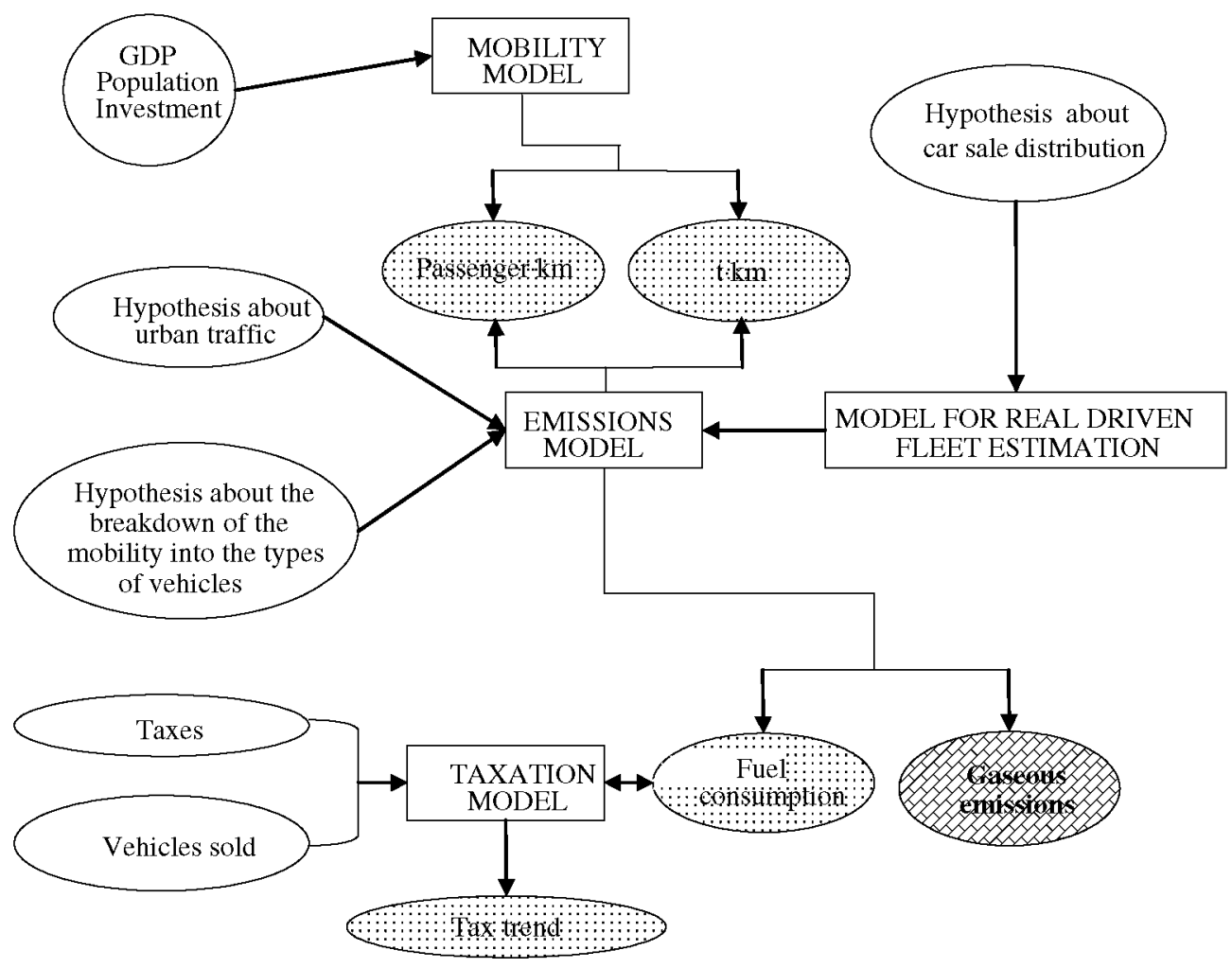

Fig. 4. Sketch of the method used to evaluate both the fuel consumption and the emission associated to each area.

- The percentage of remainder types of vehicles are calculated using the life curves of each vehicle type for Spain (Burón et al., 2005). As a result, the oldest vehicles have been decreased between 5\% and 10\% and they are substituted with new vehicles.

\section{Results}

The methodology has been applied using some data from the past years to compare the predicted emissions in these cases against official values already known. The results in Table 2 show a higher value of all pollutants

Table 2

Comparison of emissions for 2001 using the methodology presented against official values (values in tonnes)

\begin{tabular}{|c|c|c|c|c|c|c|c|}
\hline Area & Type of vehicle & $\mathrm{NO}_{x}$ & NMVOC & $\mathrm{CO}$ & $\mathrm{PM}_{2.5}$ & $\mathrm{PM}_{10}$ & $\mathrm{CO}_{2}$ \\
\hline A1 Calc & Total & 30,598 & 19,723 & 135,749 & 2024 & 2331 & $5,889,103$ \\
\hline \multirow[t]{5}{*}{ Madrid City calculated } & Cars & 7720 & 10,338 & 84,066 & & & $2,587,737$ \\
\hline & Light duty vehicles & 1980 & 721 & 5944 & & & 393,131 \\
\hline & Heavy duty vehicles + buses & 7310 & 1767 & 2600 & & & 868,334 \\
\hline & Mopeds and motorcycles & 49 & 2428 & 9261 & & & 49,448 \\
\hline & Total & 17,059 & 15,254 & 101,872 & 1334 & 1473 & $3,898,650$ \\
\hline \multirow[t]{5}{*}{ Madrid City Council (2006) } & Cars & 5866 & 7159 & 63,584 & - & - & $1,839,100$ \\
\hline & Light duty vehicles & 1668 & 469 & 4447 & - & - & 343,500 \\
\hline & Heavy duty vehicles + buses & 6167 & 1249 & 2255 & - & - & 582,800 \\
\hline & Mopeds and motorcycles & 27 & 1894 & 8669 & - & - & 43,800 \\
\hline & Total & 13,728 & 10,770 & 78,955 & - & - & $2,809,200$ \\
\hline Novotec (2004) & Total & 22,585 & 18,908 & 86,198 & 1376 & 1591 & $4,268,000$ \\
\hline
\end{tabular}


compared with the data available from the Madrid Inventory (Madrid City Council, 2006). However, checking the results against a study done for the City Council by a consultant (Novotec, 2004) the figures are lower than their estimates for all the pollutants except CO. Regarding particulate matter emissions, the official inventory does not estimate any value and our results are similar to the (Novotec, 2004) figures $(-3 \%$ for $\mathrm{PM}_{2.5}$ and $-7 \%$ for $\mathrm{PM}_{10}$ ).

The $\mathrm{SO}_{2}, \mathrm{NO}_{x}, \mathrm{NMVOC}$ and $\mathrm{CO}_{2}$ emissions associated to the base scenario in the Greater Madrid Area (Area 1) are shown in Fig. 5. Regarding $\mathrm{SO}_{2}$ emissions, they decrease during the period with abrupt changes in years 2000, 2005 and 2010 which are due to the entry into force of new sulphur content restrictions included in the Directive 98/70/CE relating to the quality of petrol and diesel fuels modified by the Directive 2003/17/CE.

As shown in the introduction, road transport is the most important source for $\mathrm{NO}_{x}$ emissions in Madrid. Fig. 5 shows $\mathrm{NO}_{x}$ emissions trend (a $5 \%$ decreasing average per year) as a result of engine technological improvements expected in the future years linked to the use of EURO IV and EURO V vehicles. The same evolution applies for the NMVOC emissions with higher decrease $(6.5 \%$ per year).

With respect to $\mathrm{CO}_{2}$, road transport is also one of the greatest sources of emission in Madrid (according to Madrid City Council, 2005 it accounted for $50 \%$ of the total $\mathrm{CO}_{2}$ emissions). Traffic $\mathrm{CO}_{2}$ emissions will increase in 2012 a $16 \%$ in respect with 2002 due to the expected increase in both passenger and freight mobility. For $\mathrm{CO}_{2}$, the technology improvement will not be able to counteract the effect of such a high mobility increment.

Specific emissions for the other zones considered (Areas 2-4, i.e. the rings and the old city centre) are illustrated in Fig. 6. It is shown that trends are very similar to those evaluated for the greater area (Area 1) except for $\mathrm{CO}_{2}$ emissions. This is because the City congestion does not allow for a high increment in the mileage traveled. Ammonia emissions show an increase up to 2007 due to the introduction of Euro III technologies, with catalyst converters that produce higher emissions. This technology penetration leads to a decrease in $\mathrm{NO}_{x}$ emissions. Regarding PM emissions, they are anticipated to be reduced regardless of the increase in the number of diesel cars. This fact shows the effect of the inclusion of particulate traps in the new cars associated to Euro legislation.
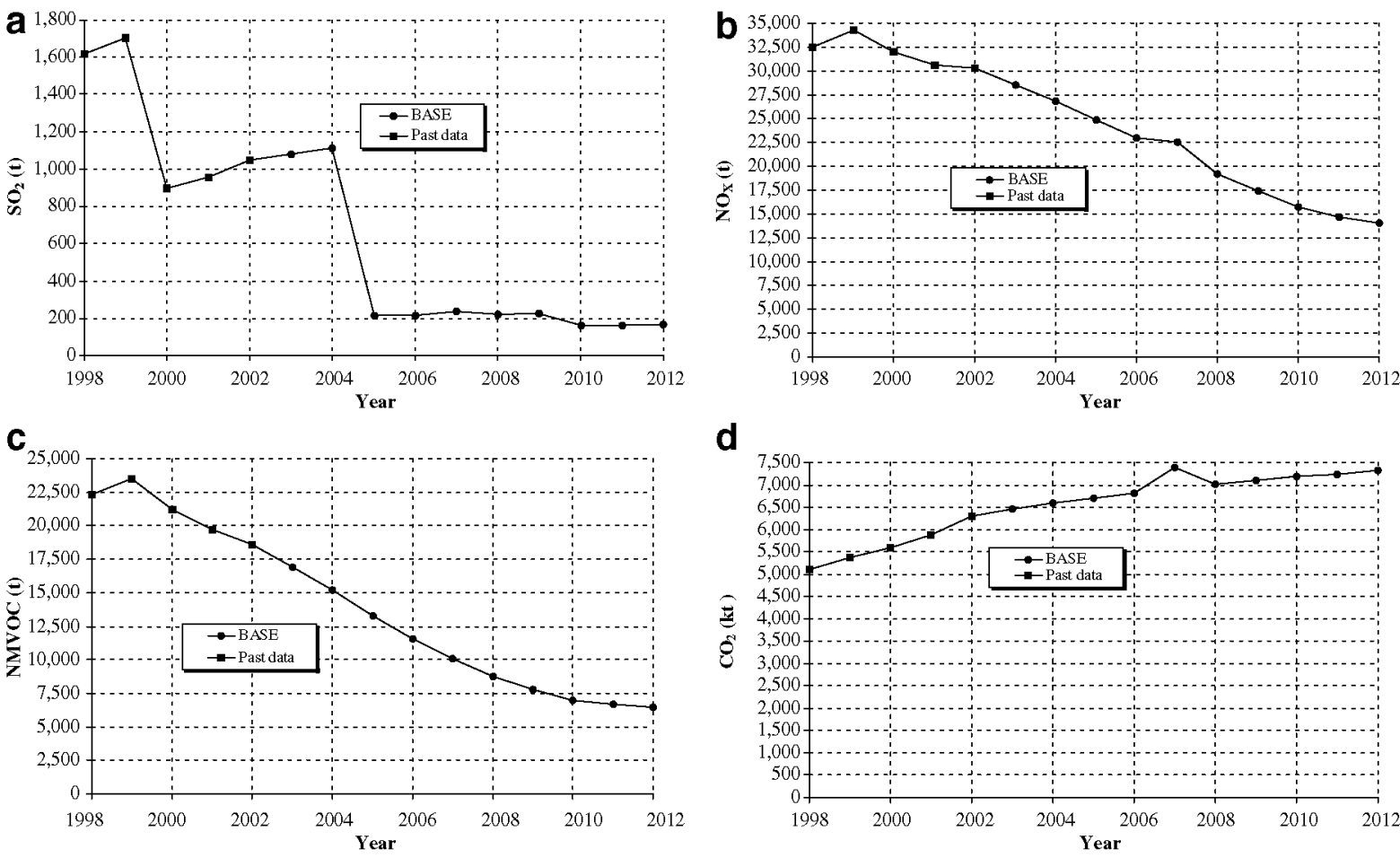

Fig. 5. Emissions from the base scenario for the Greater Madrid Area (A1). 

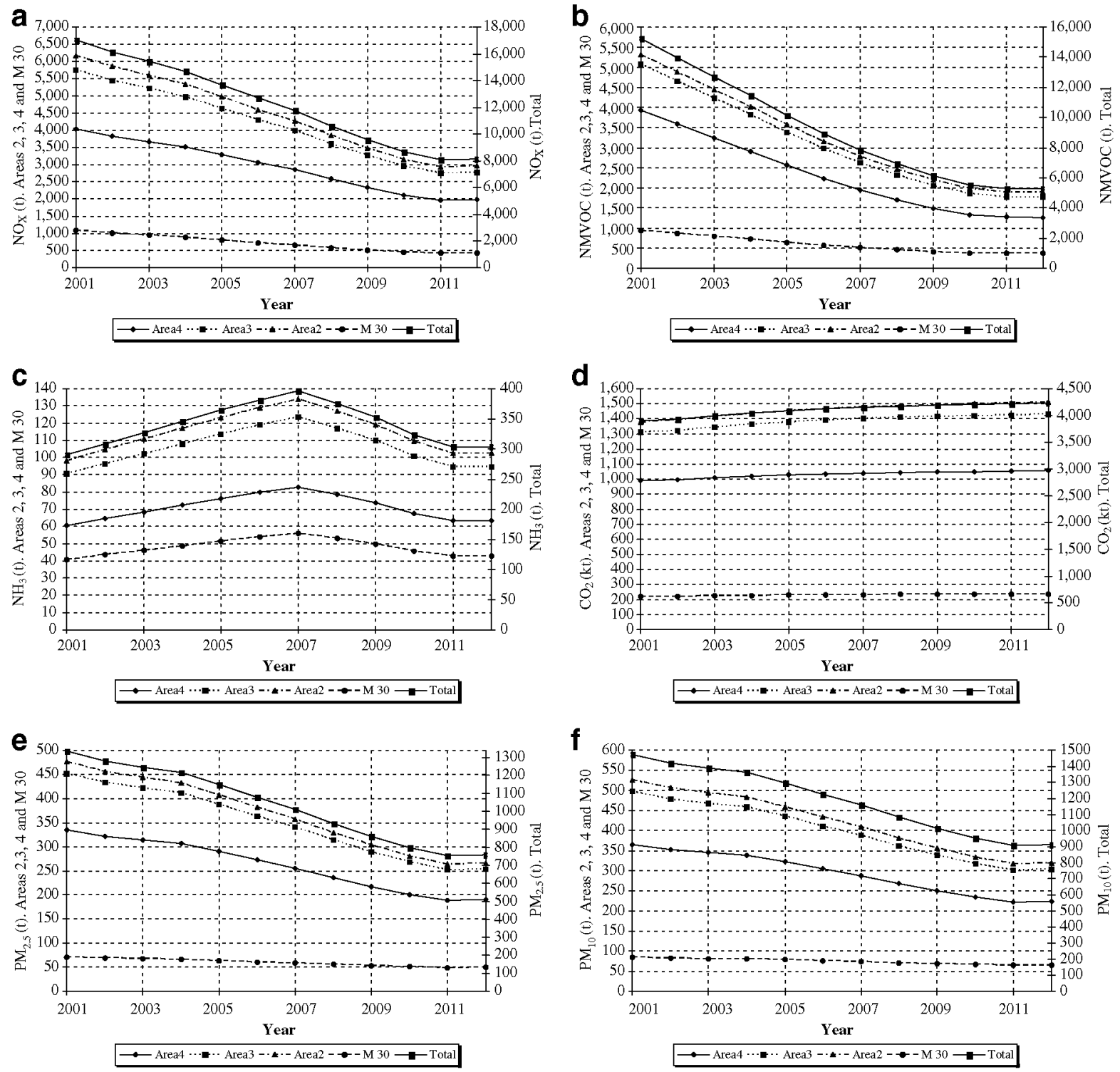

Fig. 6. Emissions for the areas within Madrid: (a) $\mathrm{NO}_{x}$ emissions, (b) $\mathrm{NMVOC}$, (c) $\mathrm{NH}_{3}$, (d) $\mathrm{CO}_{2}$, (e) $\mathrm{PM}_{2.5}$ and (f) $\mathrm{PM}_{10}$.

Fig. 7a shows the average emission factor for each pollutant and area, providing a comparison of the emissions per kilometer traveled. Fig. $7 \mathrm{~b}$ displays the average percentage pollutant emissions for each considered area; that is, for 100 tonnes of the total emission of each pollutant how much is emitted in each area. It is proved that, although the highest amounts of emissions are produced under the second ring (Area 2) $-35 \%$ of total emissions as an average-, the most polluted area is the old city centre (Area 4). In that part of the city each vehicle has a higher emission factor per kilometer, mainly due to the lower average speed. Moreover, the figure presents a lower emission factor associated for the motorway ring ("M30") since the driving pattern is completely different (rural vs. urban) and the average speed is more than three times higher for most of the vehicles (as shown in Table 1). That leads to an emission factor which varies from $45 \%$ lower for $\mathrm{PM}_{10}$ and NMVOC to $55 \%$ lower for CO compared with Areas 2-4 (i.e. the rings and the old city centre).

Figs. 8 and 9 present the emission scenarios. The first one shows the values for the Greater Madrid Area (Area 1) while Fig. 9 shows the values for the smaller interior zones (with their specific traffic patterns, average speed and fleet composition). 
a

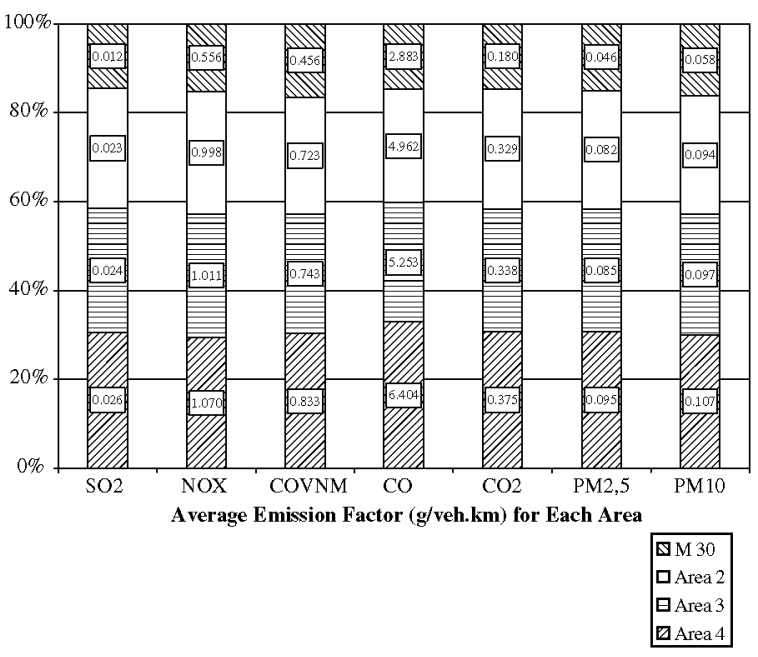

b

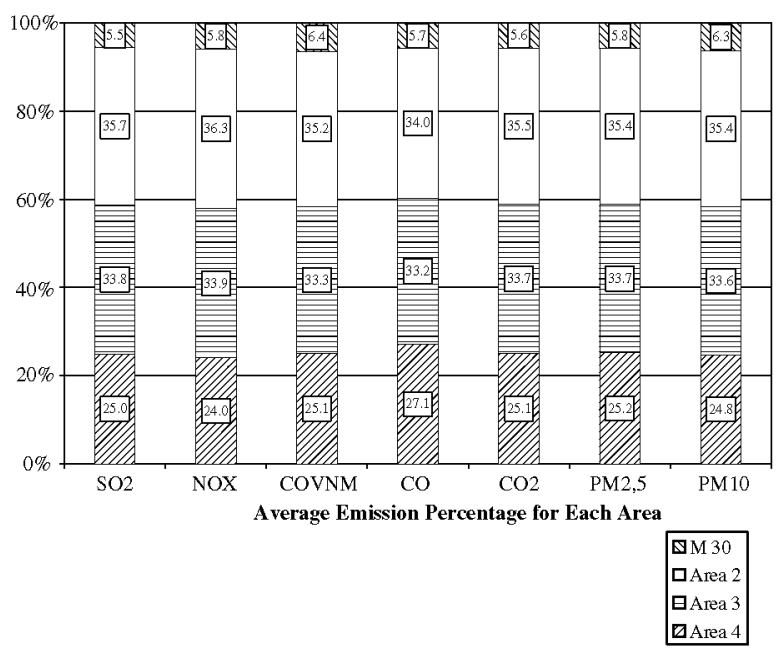

Fig. 7. (a) Emission factor per vehicle and kilometer driven in each zone and (b) percentage of emissions per area considered in the study. The values are evaluated as an average for the period 2001-2012.
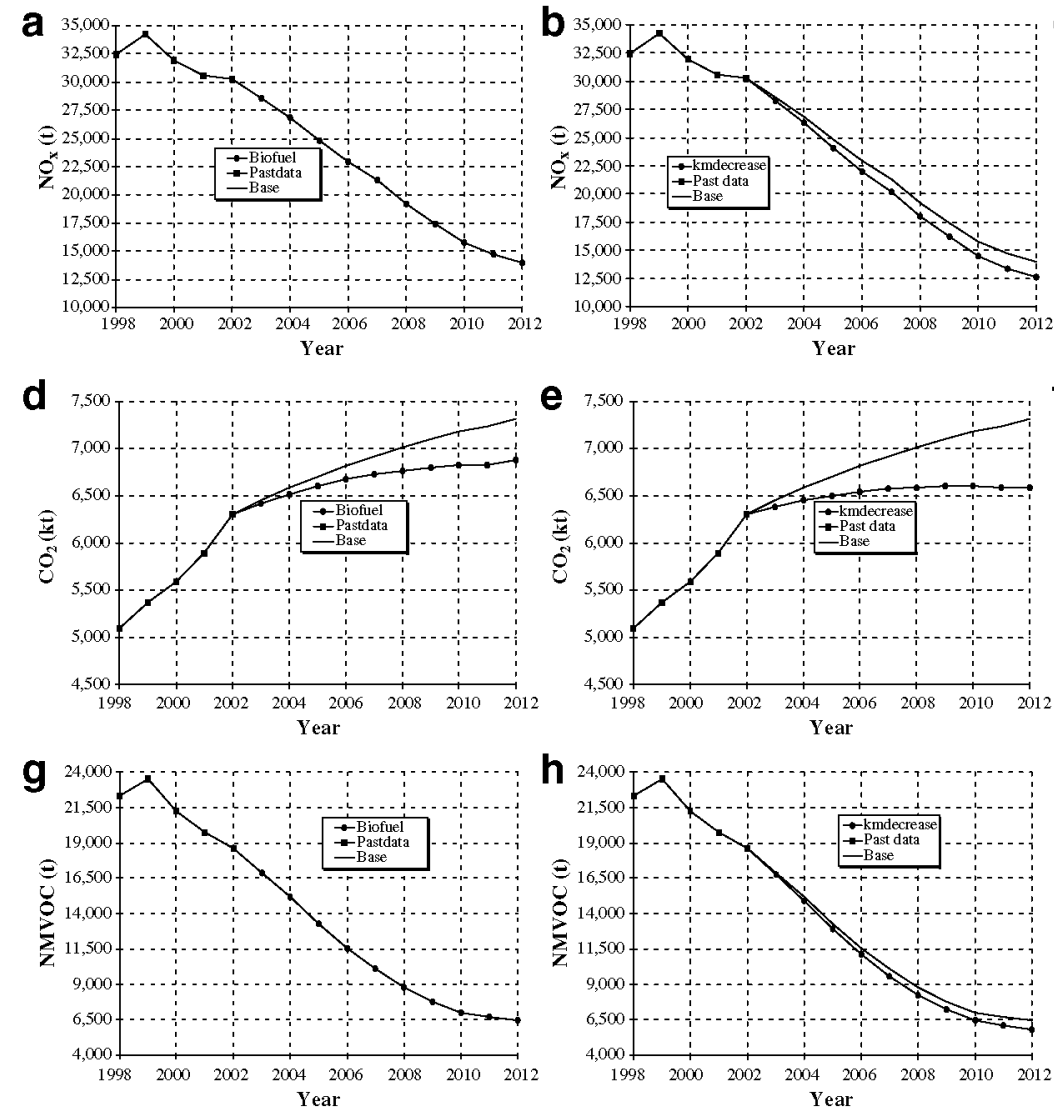

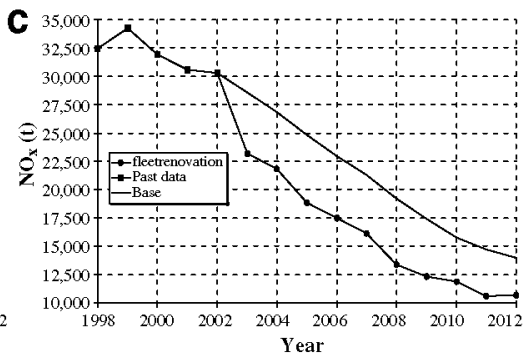

f
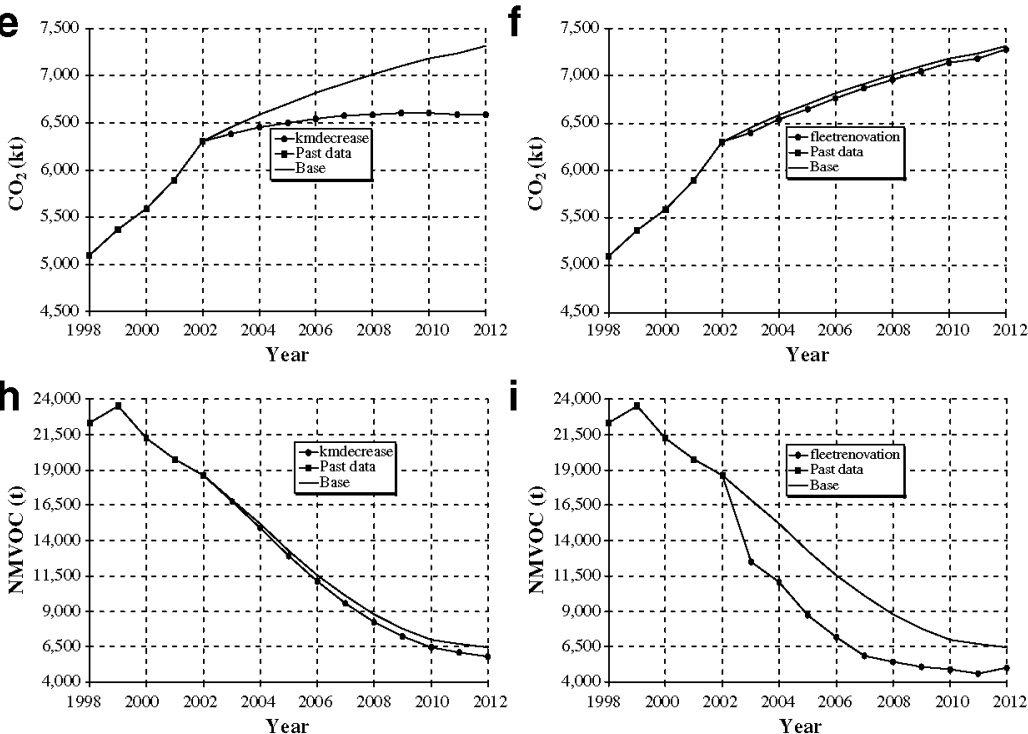

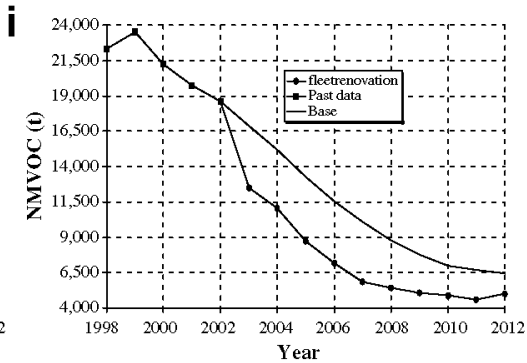

Fig. 8. Effect of measures to reduce air emissions in the Greater Madrid Area. For $\mathrm{NO}_{x}$ emissions: (a) increase of biofuels, (b) decrease in mobility and (c) fleet renovation. For $\mathrm{CO}_{2}$ : (d) increase of biofuels, (e) decrease in mobility and (f) fleet renovation. For NMVOC: (g) increase of biofuels, (h) decrease in mobility and (i) fleet renovation. 
a

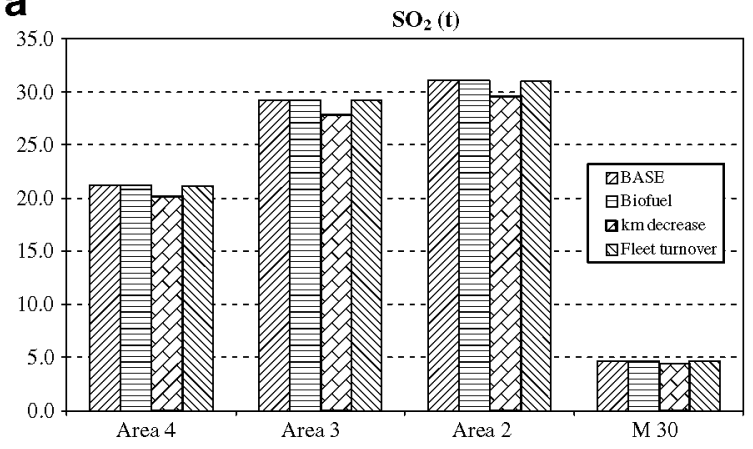

C

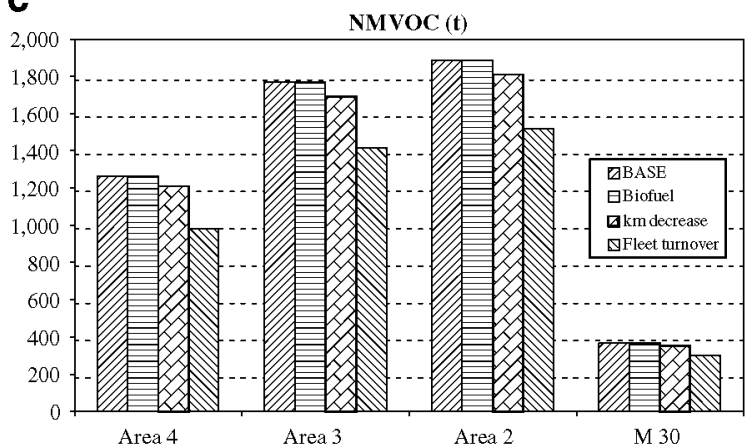

e

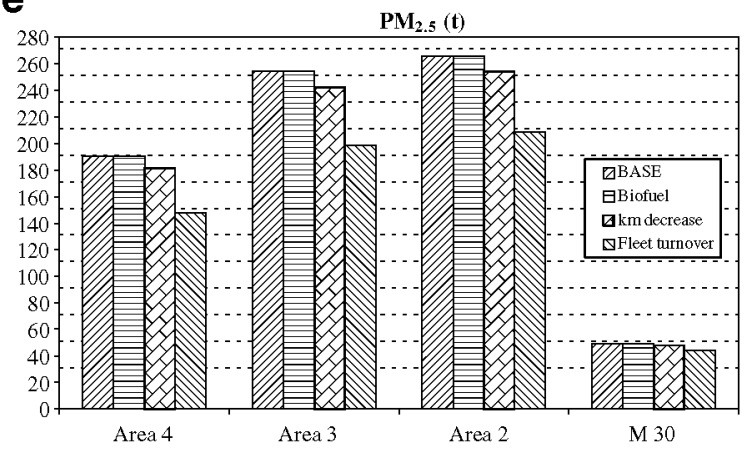

b

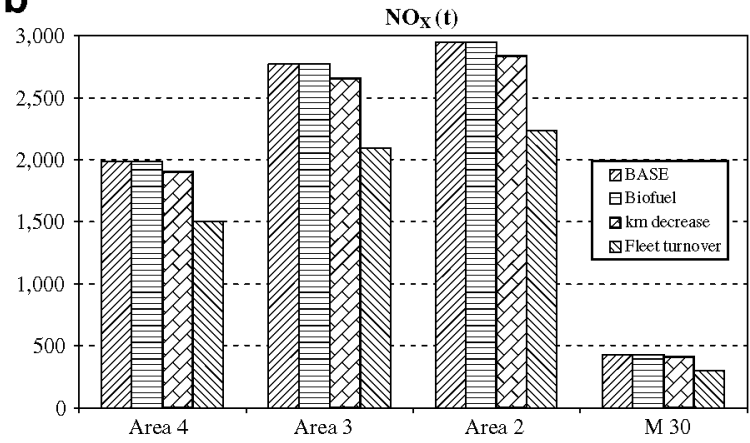

d

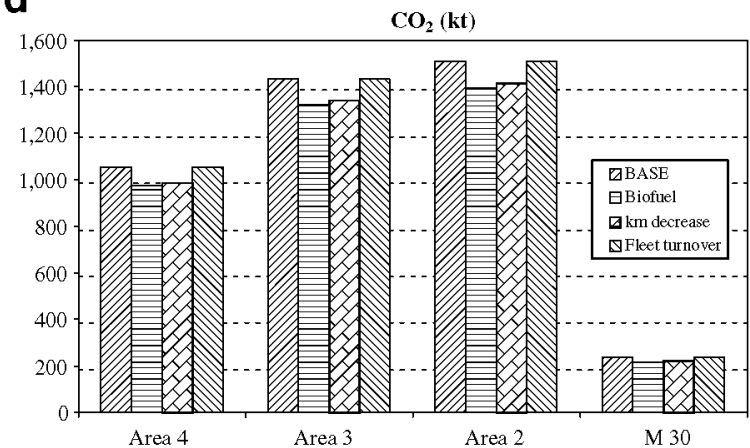

f

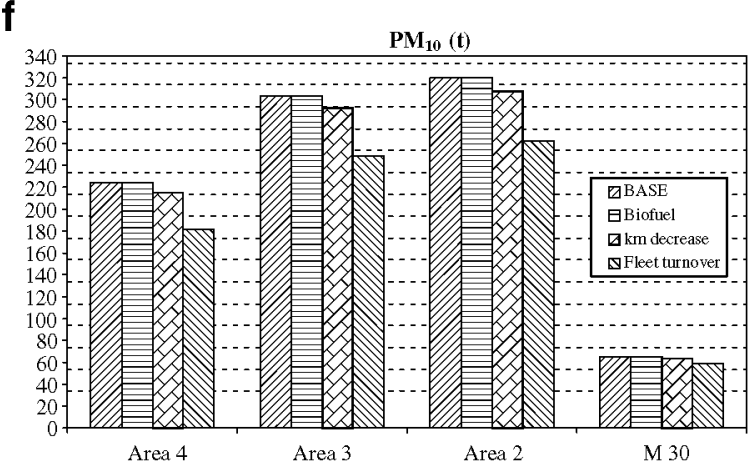

Fig. 9. Effect of the measures considered to reduce air pollution within each area: (a) $\mathrm{SO}_{2}$, (b) $\mathrm{NO}_{x}$, (c) NMVOC, (d) $\mathrm{CO}_{2}$, (e) $\mathrm{PM}_{2.5}$ and (f) $\mathrm{PM}_{10}$.

Table 3

Total Madrid emission reduction for each measure compared with the base scenario

\begin{tabular}{lrrrrrrrrrr}
\hline & $\mathrm{SO}_{2}$ & \multicolumn{1}{c}{$\mathrm{NO}_{x}$} & \multicolumn{1}{c}{$\mathrm{NMVOC}$} & \multicolumn{1}{c}{$\mathrm{CH}_{4}$} & \multicolumn{1}{c}{$\mathrm{CO}$} & $\mathrm{CO}_{2}$ & $\mathrm{~N}_{2} \mathrm{O}$ & $\mathrm{NH}_{3}$ & $\mathrm{PM}_{2.5}$ & $\mathrm{PM}_{10}$ \\
\hline Fleet renewal (\%) & 0.22 & 24.70 & 20.23 & 26.74 & 29.14 & 0.10 & 21.00 & 22.08 & 21.19 & 17.63 \\
Mileage reduction (\%) & 4.89 & 4.16 & 4.19 & 6.45 & 8.00 & 6.53 & 8.33 & 9.54 & 4.52 & 3.76 \\
\hline
\end{tabular}

For the Greater Madrid Area (Fig. 8), biofuel use is only efficient to reduce $\mathrm{CO}_{2}$ emissions (a $6 \%$ lower emission in 2012 referred to 2003 emissions). The fleet renewal is the most effective action for reducing $\mathrm{NO}_{x}$ and NMVOC (a reduction of $23.75 \%$ and $22.19 \%$ respectively) while its impact on $\mathrm{CO}_{2}$ emissions is very low (a decrease of $0.55 \%$ ). Regarding the decrease in $\mathrm{km}$ traveled, it produces a $10 \%$ reduction for $\mathrm{CO}_{2}$ and $\mathrm{NO}_{x}$ emissions and a $9.6 \%$ reduction of NMVOC.

Concerning the area-specific emissions (Fig. 9), only values for 2012 are presented in order to see the effect at the end of the period. In this case, the fleet renewal appears as the most effective measure to reduce air 
pollutants, apart from $\mathrm{SO}_{2}$. For $\mathrm{SO}_{2}$ and $\mathrm{CO}_{2}$ emissions the reduction on kilometers driven is more effective but it can only reduce the emissions by $4.9 \%$ and $6.5 \%$ respectively. As an average, for all the pollutants studied, the biofuel measure reduces the emissions by $0.64 \%$ while $\mathrm{km}$ reduction reduces it by $6.07 \%$ and fleet renewal by $16.04 \%$. Table 3 shows the comparison of the efficiency of fleet renewal and mileage reduction.

\section{Conclusions}

Future vehicle emissions in Madrid (Spain) were evaluated for the period 20042012 under several control scenarios to show the most likely outcome and the influence of technical and socioeconomic measures in an urban context.

The most likely scenario for the future consists of an increase of mobility for this period but a decrease of the emissions for most of the pollutants. This reduction is due to technological improvements linked to trafficrelated European Legislation (Euro III-V). However, $\mathrm{CO}_{2}$ emissions are expected to increase in the studied period because the technological improvements will not be able to counteract the effect of a large mobility increase.

The paper presents the effectiveness of different control strategies in reducing the emissions of $\mathrm{CO}_{2}, \mathrm{NO}_{x}$, $\mathrm{SO}_{2}, \mathrm{CO}, \mathrm{NMVOC}, \mathrm{NH}_{3}$ and Particulate Matter. The most effective measure for reducing $\mathrm{NO}_{x}, \mathrm{PM}_{10}, \mathrm{PM}_{2.5}$, $\mathrm{CO}$ and NMVOC emissions is fleet renewal. For the city of Madrid this reduction could be $24.70 \%, 17.63 \%$, $21.19 \%, 29.14 \%$ and $20.23 \%$, respectively. With regard to $\mathrm{SO}_{2}$ the most effective measure for reducing its emissions is to decrease the total number of $\mathrm{km}$ driven. In this case, a $10 \%$ reduction in mileage leads to a $4.89 \%$ lower emission level. As for greenhouse gases, biofuel introduction is the most effective control measure, decreasing $\mathrm{CO}_{2}$ equivalent emissions by $7.73 \%$. Taking into account all the considered pollutants $\left(\mathrm{SO}_{2}\right.$, $\mathrm{NO}_{x}, \mathrm{NMVOC}, \mathrm{CH}_{4}, \mathrm{CO}, \mathrm{CO}_{2}, \mathrm{~N}_{2} \mathrm{O}, \mathrm{NH}_{3}, \mathrm{~Pb}, \mathrm{PM}_{2.5}, \mathrm{PM}_{10}$ and TSP) at the same time, the most effective way to reduce emissions is fleet renewal. In the case of Madrid, it would reduce emission levels by $16.04 \%$ as an average.

Therefore, a combination of different control strategies such as fleet renewal, use of biofuels, etc. may be more effective in improving air quality in Madrid.

\section{References}

Alberini, A., Harrington, W., McConnell, V., 1996. Estimating an emissions supply function from accelerated vehicle retirement programs. The Review of Economics and Statistics 78 (2), 251-265.

Aríztegui, J., Casanova, J., Valdés, M., 2004. A structured methodology to calculate traffic emissions inventories for city centres. Science of the Total Environment 334, 101-109.

Beaton, S., Bishop, G., Zhang, Y., Ashbaugh, L., Lawson, D., Stedman, D., 1995. On-road vehicle emissions - regulations, costs, and benefits. Science 268 (5213), 991-993.

Burón, J.M., Aparicio, F., Izquierdo, O., Gómez, A., López, I., 2005. Estimation of the input data for the prediction of road transportation emissions in Spain from 2000 to 2010 considering several scenarios. Atmospheric Environment 39, 5585-5596.

Colvile, R.N., Hutchinson, E.J., Mindell, J.S., Warren, R.F., 2001. The transport sector as a source of air pollution. Atmospheric Environment 35, 1537-1565.

Comunidad de Madrid, 2005. Anuario Estadístico de la Comunidad. Conserjería de Economía e Innovación Tecnológica, Madrid (published in Spanish).

Dill, J., 2004. Estimating emissions reductions from accelerated vehicle retirement programs. Transportation Research Part D 10 (2), 87 106.

European Environment Agency (EEA), 2000. COPERT III Computer program to calculate emissions from road transport. Technical reports numbers 49 and 50, Copenhagen, Denmark.

European Union (EU), 1998. Directive 98/69/EC of the European Parliament and of the Council of 13 October 1998 relating to measures to be taken against air pollution by emissions from motor vehicles and amending Council Directive 70/220/EEC.

European Union (EU), 2002. Commission Directive 2002/80/EC of 3 October 2002 adapting to technical progress Council Directive $70 /$ 220/EEC relating to measures to be taken against air pollution by emissions from motor vehicles. 
European Union (EU), 2005a. CAFE Program. Web page and main documents at the site: <http://www.europa.eu.int/comm/ environment/air/cafe/index.htm> (page visited for last time 23rd January 2006).

European Union (EU), 2005b. COM (2005) 683 final. Proposal for a regulation of the European Parliament and of the Council on type approval of motor vehicles with respect to emissions and on access to vehicle repair information.

Hao, J., Jingnan, H., Fu, L., 2006. Controlling vehicular emissions in Beijing during the last decade. Transportation Research Part A 40, 639-651.

Instituto Nacional de Estadística (INE), 2005. GDP and population projections. Available from: <www.ine.es> (in Spanish, page visited for last time 4th October 2005).

Lisandro, O., Sampayo, A.R., 1997. Los efectos de los Planes Renove y Prever sobre el reemplazo de turismos. FEDEA (published in Spanish).

Lumbreras, J., Borge, R., de Andres, J.M., Rodriguez, E., 2008. A model to calculate consistent atmospheric emission projections. Application to Spain. Atmospheric Environment, in press.

Madrid City Council, 2005. Anuario estadístico 2005. Internal report. Available from: $<$ http://www.munimadrid.es/estadistica/ $>$ (page visited for last time 4th October 2005).

Madrid City Council, 2006. Official Emission Inventory from the City Council. Data published at $<$ http://www.mambiente.munimadrid.es/> (page visited for last time 23rd August 2006).

Spanish Ministry of Environment (MMA), 2005. Spain's Emission Inventory. CORINE-AIRE 1990-2003. Report of the Ministerio de Medioambiente, Madrid (Published in Spanish).

Novotec, 2004. Independent study of the emissions from the city of Madrid for the City Council. Novotec, Madrid.

Sælensminde, K., 2004. Cost-benefit analyses of walking and cycling track networks taking into account insecurity, health effects and external costs of motorized traffic. Transportation Research Part A 38, 593-606.

Seika, M., Harrison, R.M., Metz, N., 1998. Effects of traffic-related control strategies on urban air quality. International Journal of Vehicle Design 20, 313-325.

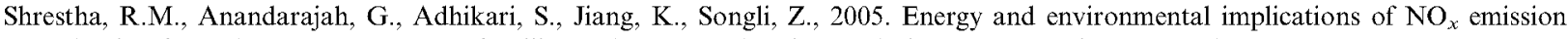
reduction from the transport sector of Beijing: a least-cost planning analysis. Transportation Research Part D $10,1-11$.

Van Wee, B., Moll, H.C., Dirks, J., 2000. Environmental impact of scrapping old cars. Transportation Research Part D 5 (2), 137-143. 